\title{
Levinas e Kant: um estudo a partir da autonomia e heteronomia
}

\author{
Levinas e Kant: a study from the \\ autonomy and heteronomy
}

\section{Silvestre Grzibowski}

Doutor em Filosofia pela Universidad Pontifícia de Salamanca - Espanha, e-mail: silboski@yahoo.com.br

\section{Resumo}

Este estudo reúne o pensamento de dois grandes filósofos que são apreciados pela crítica filosófica, Levinas e Kant. Sendo dois ícones da história da Filosofia, o pensamento é extremamente complexo e vasto. Habitualmente estes dois grandes pensadores são mencionados pela similaridade dos temas que desenvolveram, ou seja, a moral, ética e religião. Nesta pesquisa levarei em consideração estes pontos no segundo momento, já que no primeiro estarei focado na constituição do sujeito. Lembro que, a finalidade desta pesquisa não é fazer um estudo comparativo, mas a forma como os filósofos desenvolveram seus pensamentos sobre a autonomia e a heteronomia. Assim, aparecerão alguns pontos convergentes e divergentes. O sujeito kantiano é constituído por uma vontade autônoma. A autonomia da razão pode determinar-se e atuar à base dos imperativos. Kant estabelece a moral (razão) como fundamento para a relação do indivíduo com Deus, de modo que a 
religião e Deus estão subordinados à autonomia da razão prática, por isso o seu projeto, a religião dentro dos limites da razão. Já Levinas, um judeu pensador inspirado na filosofia grega e na literatura talmúdica, defende que a relação com o totalmente outro está alicerçada na heteronomia.

Palavras-chave: Autonomia. Heteronomia. Razão. Moral. Religião.

\section{Abstract}

This study brings together the thought of two great philosophers who are appreciated by the philosophical critique, Levinas and Kant. Being two icons of the history of philosophy, thought is extremely complex and vast. Usually these two great thinkers are mentioned by the similarity of the themes that have developed, or morals, ethics and religion. In this research I will take into account these points in the second time since the first will be focused on subjectivity. I remember that the purpose of this research is not to make a comparative study, but the way philosophers have developed their thoughts on autonomy and heteronomy. Thus, there will some convergent and divergent. The Kantian subject is constituted by an autonomous will. The autonomy of reason can establish themselves and act based on the imperatives. Kant establishes the moral (right) as the foundation for the individual's relationship with God, so that religion and God are contingent upon the autonomy of practical reason why your project, the religion within the bounds of reason. Since Levinas, a Jewish thinker, inspired by Greek philosophy and Talmudic literature maintains that the relationship with the wholly other is based on heteronomy.

Keywords: Autonomy. Heteronomy. Reason. Morality. Religion.

\section{Introdução}

Neste estudo vou apresentar paralelamente a autonomia da razão de Kant e a heteronomia de Levinas. Não tenho por finalidade fazer um estudo comparativo nem de juízo. O ponto de argumentação será a filosofia de Levinas.

Inicio mostrando as convergências entre os dois pensadores. Isso, a princípio, pode resultar estranho, e consequentemente vem o questionamento: existe alguma convergência entre ambos os filósofos? Ainda que pouca, existe. 
Esses aspectos serão abordados nos primeiros parágrafos, os quais se chamam de proximidade. No segundo momento, desenvolvo e enfatizo as consequências que a autonomia da razão kantiana tem trazido para a cultura ocidental. Por conseguinte, a morte de Deus ou uma religião sem Deus e a seguinte questão: um reino sem Deus não é produto da autonomia da pura razão? Depois da proclamação da "morte de Deus", o mundo tem experimentado inúmeras guerras e catástrofes humanitárias. Em meio à cinza surge o pensamento levinasiano propondo outro modo de relacionar-se com a transcendência e com o outro - a heteronomia. Segundo o pensador lituano, a filosofia ocidental confiou demasiadamente na autonomia da razão. Desse modo, prossigo, mostrando a heteronomia do sujeito e a responsabilidade ética.

Por último, perpetro algumas considerações finais, enfocando o outro modo de pensar levinasiano, que resulta um pouco estranho à nossa mente; talvez isso se deva ao fato de que fomos (somos) acostumados a pensar e a decidir sempre moralmente e religiosamente a partir dos interesses próprios. Levinas propõe que o sujeito da ação seja outro.

\section{Proximidade}

A relação entre os dois pensadores tem sido de proximidade e distanciamento, como têm observado alguns críticos, de modo especial Jan Greef (1969, p. 432-433). Diante desses estudos que já foram realizados, sigo a hipótese do rompimento, isso porque Levinas (1974, p. 166, p. 225-226) rompe em definitivo com a arquitetura kantiana, porém, não significa em hipótese alguma negar a sua relevância filosófica, porque existem alguns pontos de convergência entre ambos e pontos de divergência.

Porém, antes de tudo, gostaria de destacar o ponto que aproxima o pensamento de Kant e Levinas, esse o considera como sendo uma sincera revolução copernicana, quer dizer que o sentido último do humano não é a medida pela ontologia, mas pela ética. Tanto em Kant como em Levinas o primado, ou o princípio, reenvia à ética, à moral - em outras palavras, à filosofia prática. Ou seja, a modalidade concreta na qual acontece a relação não é ontológica, e sim ético-religiosa. Abordam a religião ou o transcendente a partir da razão prática, da vivência concreta. ${ }^{1}$ Tampouco, em ambos os filósofos

1 Estou consciente que de existem diferenças, no entanto, não podemos negar que existem muitas convergências. 
existe a preocupação de provar a existência de Deus, ou fazer teodiceia, como destaca Chalier:

a marcha filosófica de Levinas como a de Kant não pressupõe nenhuma prova a existência de Deus e não conduz a elaboração de nenhuma teologia positiva e nem negativa [...]. Ele não elabora nenhum discurso sobre Deus, não fala Dele, senão que evoca o a-Deus entanto que corolário indispensável e irrecusável de uma reflexão sobre o sentido (CHALIER, 1998, p. 186).

Deste modo, por um lado, Levinas se sente particularmente próximo da filosofia prática de Kant, na medida em que aceita e considera o acontecimento de sociedade ou a transcendência irredutível à compreensão ou a todo e qualquer exercício de poder, como a religião com seus ecos kantianos. Qualquer um pode dizer que, considerando a religião em convergência com a epifania de altura ou vestígio onde o Bem pode se revelar. Nesse sentido, Levinas se encontra próximo de uma religião nos limites da razão. Por outro lado, é importante dizer que, na reflexão sobre a revelação a partir da tradição judaica, Levinas subordina radicalmente a racionalidade da dimensão kantiana, e parte, ou se fundamenta a partir da tradição judaica-profética, sapiencial e dos escritos talmúdicos.

Portanto, tanto em Kant como em Levinas, a verdadeira proximidade de Alteridade poderia ser a ética. Com essa hipótese trabalha Jean Lacroix, ao comentar o livro Totalité et Infini. Ele diz que "a raiz mesma do pensamento de Levinas é Kantiana, porque nele não existe o verdadeiro conhecimento do outro, que a ética" (LACROIX, 1966, p. 127). No entanto, por mais que exista certa semelhança quanto à conduta moral-ética entre ambos, o problema reside no princípio, na origem, ou seja, na constituição do sujeito, poderíamos dizer no modo, ou na maneira de atuar do sujeito, como veremos no que toca, principalmente, a questão da liberdade da autonomia e heteronomia do sujeito e a pré-reflexibilidade. Abordo este aspecto no item seguinte.

\section{Heteronomia em contraposição à autonomia}

Levinas e Kant são filósofos que tratam da conduta moral e da ética do indivíduo com relação ao outro. E é exatamente por isso que, neste momento, devemos perguntar-nos a respeito do comportamento moral diante da 
alteridade, ao rosto do outro, o eu diante do outro como é ou deve ser o comportamento moral; qual é e como deve ser o comportamento moral do sujeito diante do encontro com a exterioridade? Talvez, o diálogo entre ambos os filósofos deva começar com esta pergunta, isso porque ambos não compartilham da mesma ideia sobre o atuar do sujeito. Como vimos, Kant estabelece um princípio para o comportamento moral e, consequentemente, para a filosofia da religião. Porque em Kant, somente o fato da liberdade permite fundar a autonomia da moral e o imperativo categórico. Liberdade que determina primeiramente o agir a partir da boa vontade, ser racional e autônomo. O sujeito deve estar animado de uma boa vontade, de uma intenção profunda de cumprir com o seu dever, sem importar-se com o que possa suceder fazendo abstração a qualquer outra consideração, somente este acede à moralidade como expressa Kant. "Nem no mundo, nem, em geral, tampouco fora do mundo, é possível pensar nada que possa considerar-se como bom sem restrição, a não ser tão só uma boa vontade (Ein guter Wille)" (KANT, 1975, p. 21, grifo nosso). Assim, afirma que toda pessoa sincera admite este princípio. E esta boa vontade procede da razão. E ainda, construir "a liberdade é a pedra angular de sua moral" (CHALIER, 1998, p. 192). Refutando que Deus esteja presente no mundo, na natureza ou na história, o homem deve atuar com medo e movido pelo medo na esperança de alguma retribuição. Pois, respeitando a lei moral e vivendo conforme a lei, existe a esperança de uma retribuição.

Em efeito, para Kant, a partir da determinação da vontade por sua própria lei se prova a autonomia da razão. De modo que, segundo ele, se o imperativo categórico fundamental reclama que ele possa agir sempre a partir de uma máxima tal como um poder querer. Assim, a liberdade constitui o esquema entre vontade e razão. Dessa, vem a lei à qual eu me submeto. Dessa forma, em Kant a moral deve bastar-se, ela mesma, como a liberdade. Ela se prova autônoma por excelência.

A moral é fundada sobre o conceito de um ser livre se conectando pela sua razão a lei, incondicional; ela não tem necessidade de uma idéia de um ser superior ao homem porque o homem pode conhecer o seu dever, nem de outro móbile que a lei ela mesma para que ele observe. Neste sentido, ela por si própria se basta (DELBOS, 1969, p. 481).

Sobre este tema Levinas se manifesta diversas vezes, e aqui se torna oportuno fazer uma referência, que com grande estilo diz o que significam em Kant estes termos, ou seja, o poder da liberdade e a autonomia do sujeito moral. 
L'action morale est caractérisée par as maxime universelle, détermination da la volonté qui, agissant en conformité avec loi, agit librement. Cette liberté remonte à la Raison, à l'universalité de la maxime. L'action morale dans sa liberté signifie l'indépendance vis-à-vis de toute divinité, de tout au-delà (Kant décrit le divin à partir de l'action libre): nous sommes intérieurement liés par l'obligation morale du devoir, dit Kant. Dieu n'est pas nécessaire à l'acte moral - c'est au contraire à partir de l'acte moral qu'on peut le décrire. Il devient nécessaire si, par-delà l'acte moral, nous désirons le bonheur (LEVINAS, 1991, p. 76-77).

Essa teoria vem trazer sérias consequências para o pensamento ocidental, para a própria concepção da moral ou do comportamento moral dos indivíduos e do estado. E ainda, outro tema para não dizer problema que tem trazido sérias dificuldades para o pensamento ocidental, como o da morte de Deus, ou um reino sem Deus. Não há dúvidas de que para o autor lituano o poder da liberdade e da autonomia em Kant sinaliza para uma violência no que diz respeito à constituição do sujeito moral e também para a questão da morte de Deus na sociedade ocidental. Isso porque Kant (1989, p. 101) valoriza a moral e afirma que "cada um há de proceder como se tudo dependesse dele, e somente sob esta condição pode esperar que uma sabedoria superior conceda a seus bens intencionados esforços de consumação".

Nota-se que, para esse filósofo alemão, Deus e religião estão subordinados à moral. Avançando ainda mais, dirá que é preciso que Deus não esteja no mundo para que o sujeito tenha a possibilidade de comportar-se moralmente. Ou para comportar-se não é preciso voltar-se para Deus, ou comportar-se como se ele não existisse, e somente consultar a voz da razão, pois é ela quem dita a boa conduta.

Portanto, a moral depende somente da razão, e esta razão não necessita de Deus e também não necessita de nenhum suporte, de nenhuma comunidade-instituição, no caso, de nenhuma Igreja. Porque este pensador rejeita que o comportamento moral deva ser ditado por uma instituição ou pela Escritura. Kant (1989, p. 256) não descarta a possibilidade de utilização de uma passagem bíblica, para que o homem possa melhorar a sua conduta, mas isso não quer dizer que essa terá alguma autoridade sobre ele.

Tendo estas constatações, é possível a partir de agora perguntar: quais são os aspectos que os diferenciam? Um primeiro fator que deve ser observado é que Kant considera uma moral ou atitude (atitudes, atos) do sujeito moral como uma radical autonomia que parte de um sujeito livre sempre, 
o ponto de partida para Levinas, se é que podemos dizer assim, será sempre a heteronomia. Mas a diferença entre Kant e Levinas, como alerta Bernard Forthomme (1979, p. 249), "não reside unicamente, a este nível, em uma simples substituição de vocabulário, onde Kant nomeia autonomia, e Levinas de heteronomia". As diferenças residem na concepção de pensamento, no modo de fazer filosofia. Há que se notar também a característica da universalidade da lei que é compreendida diferentemente em uma moral de autonomia e em uma moral de heteronomia. A moral de Levinas é universal no sentido de que o rosto do outro, em sua manifestação (epifania) ou expressão, fala em nome de uma humanidade e não em seu próprio nome. E que esta universalidade fala por meio de um indivíduo concreto, de carne e osso, um ser que respira e come.

Em seguida, vemos que, por mais que os dois filósofos partam da prática e não da teoria, da conduta moral, da postura ética dos indivíduos, a diferença, ou se pode dizer, a novidade de Levinas é que só a relação com a Alteridade produz a Ética e em nenhum momento a lei tem sentido no relacionamento com o Outro, ou seja, o abandono completo da lei moral do sujeito. Para Levinas, só o outro pode colocar esta lei em mim. E assim sendo, sou responsável pelo outro sem decidir-me, sem escolher, sem pensar, a própria responsabilidade é o sujeito e dessa não posso esquivar-me. E é esta responsabilidade que traz a liberdade, enquanto que, em Kant, se dá ao inverso. Ou seja, uma diferença essencial entre os dois é que em Kant a razão só é capaz, ou deve ser capaz, de se impor à lei moral, independentemente do encontro com o outro que seria desconsiderado como um recurso à experiência. Por isso, o conceito de autonomia é central no pensamento moral de Kant, pode ser considerado como respondendo à esfera da imanência ou de totalidade descrita por Levinas, ou à esfera de interioridade do Eu que a moral coloca precisamente em questão.

A ética de Levinas é em efeito uma ética de heteronomia que assegura a moralidade do eu. $\mathrm{O}$ indivíduo em Kant se submete a uma lei, obedece a um mandamento, mas este mandamento não vem além da razão e da vontade (GREEF, 1970, p. 432).

E, como sabemos, a racionalidade reduz o Outro ao objeto, e não oferece perspectivas para a alteridade. O Outro para Levinas, ou melhor dito, o rosto do Outro, impõe-se antes de qualquer teoria, de qualquer discernimento, e assim se forma o primeiro mandamento "sou responsável". "O rosto que se impõe sem que eu possa deixar de ser responsável por sua miséria. 
A consciência perde sua primazia" (LEVINAS, 1991, p. 9). Não há duvidas de que, neste aspecto, o nosso autor se afasta definitivamente do kantismo. Porque, como vimos, o sujeito kantiano jamais perde seu poderio diante do outro, sempre atua conforme a sua consciência (primazia), pois este sujeito "se pergunta, o que se pode fazer no caso omisso à miséria do outro, se pode querer que seu egoísmo se converta em lei universal da natureza" (CHALIER, 1998, p. 49). Já em Levinas o choque produzido se dá na epifania da miséria do rosto do outro, jamais o leva a perguntar-se que atitudes devem ser tomadas. Diante do outro, as atitudes de amor ou ódio não devem ser tomadas pelas máximas universais, como diz Fred Poché, se dá ao apelo do rosto;

[...] nem a boa vontade, nem a decisão pensável de subordinar o amor de si aos princípios morais não vem final do egoísmo. ${ }^{2}$ Somente o reencontro da fragilidade do outro [...] acontece (nele) à deposição das armas. Desfazerse do egoísmo não se anuncia a subordinação das máximas a um sujeito a universalidade do princípio moral, mas na sua submissão ao apelo do vestígio (POCHE, 1998, p. 221).

Por isso, este encontro não parte do sujeito autônomo, pois este, para Levinas, é um tirano que se encontra com o rosto frágil e débil e que clama pela minha responsabilidade.

Nesse sentido, a experiência moral que parte da proximidade, do encontro com o outro, permanece original e anárquica.

Comportar-se, e queira-se ou não, a ética se refere a algum modo de comportamento, implica já o ato de ser responsável de manter a exterioridade, e pelo mesmo a transcendência, isto é, a subjetividade. Por isso, a moralidade não é, nem a busca de princípios sólidos, nem a pergunta pela fundamentação, nem a condição de certas condições originárias. A moral é, antes de nada, uma questão de justiça (GONZALES, 1984, p. 225-226).

Partindo deste ponto, sobretudo, quando Arnaiz diz que a moral (de Levinas) não busca princípios sólidos, nem a pergunta pela fundamentação [...]; então a partir de que ponto seria possível entender a ética levinasiana já como ruptura com a moral kantiana? Ou, concretamente, como acontece a heteronomia?

2 O grifo é nosso para indicar outra tradução: não termina com o egoísmo. 
Primeiro penso que não seria possível compreender a filosofia levinasiana sem ter presente o Deus que vem da ideia (ideia do infinito); segundo, porque a ideia do infinito não é produto da razão, a ideia não é produto do finito, vem da minha ideia, portanto, está mais além dos limites da razão, além do finito e que o finito não pode contê-la. E aí adentro para um terceiro passo que seria a meu ver decisivo; a noção do infinito qualifica a relação com o Outro tanto que Outro; quer dizer, fora do retraimento do mesmo. De modo que o infinito capacita à evasão fora da limitação de mim a si mesmo. Ainda seguindo este raciocínio, a relação com absolutamente Outro ou a saída que é qualificada de infinito chamam-se responsabilidade infinita para o Outro. Segundo Levinas, o infinito ético toma sentido a partir do momento em que eu tomo as minhas responsabilidades e elas vão multiplicando-se. Exatamente por isso o nosso autor afirma que "quanto mais me aproximo do Outro na responsabilidade absoluta ou infinita, mais a distancia se amplia" (LEVINAS, 1974, p. 184). No sentido de que quanto mais me aproximo, mais responsável sou e aumenta cada vez mais a minha responsabilidade, sendo uma responsabilidade infinita. Esta é uma das grandes novidades do autor com relação à ética que é infinita, ou infinito ético.

Além disso, e contrariamente a Kant, Levinas pensa no sujeito que não se orienta voltando-se sobre si, ou consultando sua própria tábua de princípios - a orientação sempre procede do Outro. Não que esse Outro seja Deus, mas a responsabilidade ética a-Deus. E ainda, jamais o agir ético é semelhante ao kantiano, em que, além da morte, o sujeito esperará a felicidade que será dada proporcionalmente à sua virtude, ou conforme o comportamento moral que há tido, digamos, neste mundo. Para Levinas, este Deus está marcado pela economia e pelo cálculo. A responsabilidade para o outro não deve estar marcada por interesses próprios ou como algo que aguarda uma recompensa ou um salário da parte de um Deus. Diz Levinas que convém atuar sem confiar que se vá entrar na Terra Prometida, como há sucedido com Moisés.

Outro aspecto que há de ser considerado, portanto, é a descrição que ele oferece do momento responsável, quer dizer a ética como resposta do $\mathrm{Eu}$ ao Outro, se faz em termos pré-reflexíveis, quer dizer a resistência ao movimento de recuperação pela visão totalizante. Porque este movimento de irreflexão Levinas chama de pré-intencionalidade, ou pré-metafísico, anterioridade metafísica, a ética se joga antes e contra a lucidez da consciência. Nesse sentido, para Levinas a ética é irreflexível, não surge depois de ter colocado em questão a reflexão para que seja entendida, mas ela é irrecuperável pela reflexão. Isto significa a impossibilidade de teorizar uma ação. Levinas insistirá que a irreflexão não é reflexível e recuperável a posteriori. 
Não se faz presente nem representada; alguma coisa que já tem passado por cima da cabeça do presente não tem atravessado o cordão da consciência teórica e não se deixa recuperar; algo que precede ao começo e ao princípio, que existe anarquicamente apesar do ser, inverte ou precede do ser (LEVINAS, 1987, p. 71).

A ética não pode levantar pelo domínio do pré-refletido, porque ela não vem antes da reflexão, porque constitui justamente uma resistência a reflexão.

\section{Considerações finais}

Vimos que em Kant a religião está submetida à moral, nasce a partir da moral; e em Levinas, será a religião submetida à ética? Nesse aspecto, ambos os filósofos se distanciam ainda mais, porque Levinas não aborda sobre a fé pensante, muito menos a religião dentro dos limites da razão, menos ainda sobre a livre eleição, ao contrário, sou eleito e, ainda, é certo que a ideia de Deus vem no espírito do sujeito no instante em que este responde à debilidade do próximo. Sendo assim, se Levinas pensa que a religião não fundamenta a moral, em efeito, a produção (relação) ética desenvolve a essência mesma da religião.

Porque, para a ideia levinasiana, a relação ética não pode ser compreendida, ou um Dizer não se deixa compreender; assim sucede com a exterioridade do outro, o qual não se deixa compreender pela razão, pois, para este pensador, isso significa colocar nos termos de totalização (LEVINAS, 1961, p. XIII). Ser recolhido por um discurso é entrar em uma totalidade. Pois, para Levinas, o absolutamente outro é descoberto antes de colocar em questão, antes de refletir; o outro não passa pela consciência para chegar ao outro. Esta é a questão fundamental da ética de Levinas, a dimensão do infinito que reside nos seus relacionamentos e resiste à totalização. Assim, a ética rompe e se opõe a reflexão, a tomada consciência ulterior pela razão.

Não há dúvidas, a ética para Levinas deve ser universal, mas ele refuta a reconciliação da razão como saber racional e como comportamento pensável. Não pode ter a identificação entre reflexão e moral. Porque a presença do outro não pode ser reduzida a uma presença, porque o outro é sempre alteridade e a sua alteridade não pode ser reduzida à presença ou à representação.

Nota-se, evidentemente, que nos escritos levinasianos aparece de modo claro o judaísmo, pode ser na concepção de heteronomia, como observa Catherine Chalier, nessa a autora recorda que a condição de estrangeiro está associada à 
heteronomia do mandamento que prescreve o respeito ao estrangeiro. Nesse texto, Levinas (1987, p. 96) recorda inúmeras vezes o que, segundo ele, é um "eco do dizer permanente da Bíblia: a condição - ou a incondição - de estrangeiros e escravos no país do Egito aproxima o homem do próximo". Este recordarse da debilidade leva a praticar o serviço ao próximo, sem pretender dominá-lo.

A preocupação pela própria vida e o interesse em ser - uma vez que há saído do Egito - não se convertem espontaneamente nem por decisão autônoma em preocupação pela vida dos demais e em subordinação do ser as exigências do bem. A chamada do bem - na forma dos mandamentos Eternos na Bíblia - solicita ao sujeito: não é este quem decide, não é ele quem a realiza (CHALIER, 1998, p. 94).

Ao inverso de Kant, Levinas não crê que o sujeito seja moral em razão de sua autonomia, mas antes do fato da eleição pelo rosto do outro. Porém devemos compreender que é a responsabilidade que faz a eleição.

$\mathrm{O}$ a-Deus significa que um sujeito na proximidade fraterna com seu semelhante, que é responsável, que assume a responsabilidade antes de qualquer juízo ou discernimento, atua sem esperar nenhuma reciprocidade ou recompensa. Este atuar não reclama nenhuma crença religiosa e nenhuma devoção em Deus. Tampouco exige uma elaboração teológica ou espiritual por parte do sujeito, mas dá testemunho dessa responsabilidade infinita que procede dos compromissos decididos e assumidos com total liberdade. Levinas chama esta responsabilidade de eleição. Não sou eu quem o escolhe, mas é o outro quem me elege e por quem sou responsável. De modo que a palavra "Deus" nasce na circunstância de Eis-me aqui. Estou aqui para o outro até a substituição, minha responsabilidade é infinita, até a substituição do outro.

\section{Referências}

CHALIER, C. Pour une morale au-delà du savoir. Kant et Levinas. Paris: Editions Albin Michel S.A., 1998.

DELBOS, V. La philosophie pratique de Kant. Paris: Presses Universitaires de France, 1969.

FORTHOMME, B. Une philosophie de la transcendance. La méthaphysique d’Emmanuel Lévinas. Paris: La Pensée Universelle, 1979. 
GONZALEZ, R. A. G. ¿Intuición o Responsabilidad? La constitución ética de la subjetividad en E. Levinas. In: SEMINARIO DE METAFISICA, 19., 1984, Madrid. Anales... Madrid: Seminario de Metafisica, 1984.

GREEF, J. Éthique, réflexion et histoire chez Levinas. Revue philosophique de Louvain, v. 67, n. 8 , p. 431-460, 1969.

IGREJA CATÓLICA. Papa. Benedicto XVI. Spe Salvi: carta encíclica. Madrid: Biblioteca de autores cristianos, 2007. Documentos pontifícios.

KANT, I. Fundamentación de la metafísica de los costumbres. Tradução de M. García Morente. Méjico: Porrúa, 1975.

KANT, I. La religión dentro de los límites de la mera razón. Tradução de José María Quintana Cabanas. Barcelona: PPU, 1989.

LACROIX, J. Panorama de la philosophie française contemporaine. Paris: Presses Universitaires de France, 1966.

LEVINAS, E. Totalité et Infini: essai sur l'extériorité. Den Haag: M. Nijhoff, 1961.

LEVINAS, E. Autrement qu'être ou au-delà de l'essence. Den Haag: M. Nijhoff, 1974.

LEVINAS, E. Hors sujet. Montpellier: Fata Morgana, 1987.

LEVINAS, E. Dieu, la mort et le temps. Paris: L'Herne, 1991.

POCHE, F. Chronique d'éthique, analyse du livre de Catherine Chalier Pour une morale au-delà du savoir, Kant et Levinas. Revue d'éthique et de théologie morale Le supplément, v. 17, n. 9, p. 19-23, 1998.

Recebido: 20/10/2010

Received: 10/20/2010

Aprovado: 29/10/2010

Approved: 10/29/2010 